\title{
Primary ovarian cancer cells are sensitive to the proaptotic effects of proteasome inhibitors
}

\author{
LUCA PASQUINI $^{1}$, ALESSIA PETRONELLI ${ }^{1}$, ELEONORA PETRUCCI ${ }^{1}$, ERNESTINA SAULLE $^{1}$, \\ GUALTIERO MARIANI $^{1}$, GIOVANNI SCAMBIA ${ }^{2}$, PIERLUIGI BENEDETTI-PANICI ${ }^{3}$, \\ STEFANO GREGGI $^{4}$, FRANCESCO COGNETTI ${ }^{5}$ and UGO TESTA ${ }^{1}$
}

\author{
${ }^{1}$ Department of Hematology, Oncology and Molecular Medicine, Istituto Superiore di Sanità, Viale Regina Elena 299; \\ ${ }^{2}$ Institute of Gynecology, Perinatalogy and Child Health, University 'La Sapienza' of Rome, Viale Regina Elena 324; \\ ${ }^{3}$ Department of Gynecology and Obstetrics, Catholic University, Rome; ${ }^{4}$ Obstetric and Gynecologic Oncology, \\ National Cancer Institute, Naples; ${ }^{5}$ Department of Medical Oncology, Regina Elena Cancer Institute, Rome, Italy
}

Received February 12, 2009; Accepted March 24, 2009

DOI: 10.3892/ijo_00000546

\begin{abstract}
Resistance of tumors to cell death signals poses a complex clinical problem. In the present study, we have explored the capacity of proteasome inhibitors to induce cell death of ovarian cancer cells. We explored the sensitivity of primary ovarian cancer cells to a combination of bortezomib (also known as PS-341), a proteasome inhibitor and TRAIL, a death ligand, or mapatumumab or lexatumumab, TRAIL-R1 or TRAIL-R2 targeting agonist monoclonal antibodies, respectively. The results of our study showed that the large majority of primary ovarian cancers are clearly sensitive to the pro-apoptotic action of bortezomib, whose effects are potentiated by the concomitant addition of TRAIL or mapatumumab or lexatumumab. Interestingly, both cisplatin and paclitaxel-chemosensitive and chemoresistant ovarian tumors are equally sensitive to the cytotoxic effect of bortezomib. Bortezomib, combined with TRAIL or TRAIL-R1 or TRAIL-R2 agonist monoclonal antibodies may be a useful treatment for refractory ovarian cancer.
\end{abstract}

\section{Introduction}

Epithelial ovarian cancer derives from the malignant transformation of the epithelial ovarian surface. It accounts for $\sim 90 \%$ of all the human ovarian malignancies. Ovarian cancer is the leading cause of cancer-related death in women. In fact, in women, ovarian cancer is the fourth leading cause of deaths related to cancer and represents the most lethal gynecologic malignancy with a 5-year survival of 30-40\% (1).

Correspondence to: Dr Ugo Testa, Department of Hematology and Oncology, Medical Oncology Section, Instituto Superiore di Sanità, Viale Regina Elena 299, 00161 Rome, Italy

E-mail: ugo.testa@iss.it

Key words: ovarian cancer, proteasome inhibitors
Unfortunately, ovarian cancer is often detected only after it has spread throughout the peritoneal cavity. Despite aggressive surgical resection and adjuvant therapy, most patients with advanced-stage ovarian cancer die of their malignancy (1).

Although platinum derivatives, associated with taxanes, are considered the standard first-line chemotherapeutic agents for the treatment of ovarian cancer, chemoresistance remains a major therapeutic problem and the cellular mechanisms involved in the resistance are poorly understood. More effective therapies are needed in the setting of recurrent ovarian cancer to overcome drug resistance.

Among the new agents particularly promising are the proteasome inhibitors. The ubiquitin proteasome pathway is a highly conserved intracellular pathway for the degradation of proteins. The proteasome pathway controls the half-life of short-lived regulatory proteins that play a key role in the regulation of cell proliferation, differentiation, signaling and transcription (2). The ubiquitin proteasome pathway plays an important role in neoplastic growth and metastasis. Particularly, the proteasome is also required for activation of nuclear factor $-\kappa \mathrm{B}(\mathrm{NF}-\kappa \mathrm{B})$ by degradation of its inhibitory protein, $\mathrm{I}-\kappa \mathrm{B}(3) . \mathrm{NF}-\kappa \mathrm{B}$ is a transcription factor that upregulates a number of proteins involved in cancer progression, including several proangiogenic factors and anti-apoptotic factors. Many studies have shown that proteasome inhibitors are able to induce apoptosis of tumor cells mainly via inhibition of NF-кB activity (4). In addition, there is evidence in various tumor models that proteasome inhibitors enhance the sensitivity of tumor cells to the death ligand TRAIL (5). Ovarian cancer cell lines displayed a significant sensitivity to the pro-apoptotic effects of proteasome inhibitors $(6,7)$. The analysis of the mechanisms through which proteasome inhibitors induce apoptosis of ovarian cancer cells indicate a main role of mitochondrial damage through stabilization of $\mathrm{BH} 3$-only proteins (8).

The analysis of the ubiquitin-proteasome system showed increased levels in malignant ovarian cancer cells (both cell lines and primary tumor cells) compared to their normal counterpart (9). Furthermore, there is evidence that the ubiquitin proteasome system is stressed in ovarian cancer cells 
as supported by the observation that elevated levels of total ubiquitinated proteins and proteasome subunits are observed in ovarian carcinoma tissues, compared to normal surface epithelium (9). The increased expression of proteasome in ovarian cancer cells is associated with a high sensitivity to apoptosis in response to proteasome inhibitors (9).

Importantly, a proteasome inhibitor introduced in clinical practice has been evaluated in phase I studies in ovarian cancer. The initial phase I study showed a significant antitumor activity of bortezomib (also known as PS-341 and registered for clinical use as Velcade $\left.{ }^{\circledR}\right)$, a proteasome inhibitor clinically indicated for the therapy of myeloma and mantle cell lymphoma. More recently, two additional studies have explored the safety profile and the anti-tumor activity of bortezomib when administered together with carboplatin (11) or with paclitaxel (12) to ovarian cancer patients, including patients with platinum- and taxane-resistant disease. Interestingly, some chemoresistant patients responded to treatment with bortezomib.

The death receptors of the Tumor Necrosis Factor (TNF) superfamily represent potential targets for promoting apoptosis of cancer cells (13). Among the various TNF members particularly interesting is the TNF-related apoptosis-inducing ligand (TRAIL) for its property to induce apoptotic cell death receptors via both TRAIL-R1 and TRAIL-R2, while sparing normal cells $(14,15)$. These two receptors have a cytoplasmic death domain through which TRAIL can transmit its apoptotic signal by binding as a homodimer. Because of its proposed role in inducing apoptosis in cancer cells, while sparing normal cells, several TRAIL receptor agonists have recently entered the clinic $(16,17)$. Mapatumumab and lexatumumab are fully human monoclonal antibodies that are agonistic to TRAIL-R1 and TRAIL-R2, respectively (18). Preclinical studies in mice and non-human primates, as well as phase I clinical studies in humans have shown the potential utility of recombinant TRAIL and agonistic TRAIL-R1 and TRAIL-R2 antibodies for cancer therapy (reviewed in ref. 19). However, many primary tumor cells, including ovarian cancer cells (8), are resistant to the proapoptotic effects of TRAIL. To bypass TRAIL resistance of primary tumor cells, TRAIL or agonist TRAIL-R antibodies have been combined with other agents (i.e., chemotherapeutic drugs or proteasome inhibitors) able to restore a high sensitivity of these tumor cells to TRAIL (19). In the present study, we have explored the sensitivity of primary ovarian cancer cells in vitro to proteasome inhibitors combined with TRAIL or the TRAIL-R1 and TRAIL-R2 agonistic monoclonal antibodies, mapatumumab and lexatumumab.

\section{Materials and methods}

Cell culture. Cisplatin-sensitive human ovarian epithelial carcinoma cell line A2780 was obtained from the American Type Culture Collection (ATCC); cisplatin-resistant cell line A2780/DDP and adriamycin-resistant cell line A2780/ADR, derived from its parental ovarian cancer cell line A2780 by applying stepwise increases in concentrations of cisplatin and adriamycin, respectively were obtained from the European Collection of Cell Cultures (ECACC). The A2780/DDP cells were incubated in $30 \mu \mathrm{M}$ of cisplatin and the A2780/ADR cells in $10 \mu \mathrm{M}$ adriamycin every 10 passages.
The cells were cultured at $37^{\circ} \mathrm{C}$ in an atmosphere of $5 \%$ $\mathrm{CO}_{2}$ in Advanced MEM with $3 \%$ fetal bovine serum (FBS, Euroclone, Milan, Italy), $50 \mathrm{IU} / \mathrm{ml}$ penicillin, $50 \mu \mathrm{g} / \mathrm{ml}$ streptomycin, $50 \mu \mathrm{g} / \mathrm{ml}$ gentamycin and $0.3 \mu \mathrm{g} / \mathrm{ml}$ glutamine. The cells were routinely checked for the presence of mycoplasma.

Isolation and in vitro culture of primary ovarian cancer cells. Intra-operatory biopsies were obtained from 34 ovarian serous adenocarcinoma cancer patients undergoing debulking surgery. Tumor tissue was mechanically dissociated with a scissor and a tumor cell suspension was obtained by digestion in tissue culture medium (RPMI-1640) containing collagenase, deoxyribonuclease I and hyaluronidase. The final tumor cell suspension was checked for the proportion of tumor cells by standard cytology and the percentage of epithelial cells by flow cytometry (determined after staining with Ber-EP4 mAb, Dakopatt, Copenhagen, Denmark). Tumor cell aliquots $\left(1 \times 10^{6}\right.$ cells) were plated into $25 \mathrm{~cm}^{3}$ tissue culture flasks in $10 \mathrm{ml}$ of cell culture medium containing $5 \%$ fetal calf serum. After 1 day of in vitro culture, non-adherent cells (containing tissue debris and dead cells) were removed and fresh medium was added to the culture and then incubated for additional $24 \mathrm{~h}$ either in the absence or in the presence of TRAIL, or bortezomib or both reagents. At $24 \mathrm{~h}$ of culture cells were confluent. Tumor cultures contained at least $80 \%$ of tumor cells.

In vitro extreme drug resistance. In vitro response to anticancer drugs was assessed by the Oncotech EDR assay $(20,21)$. Surgical biopsies (1-2 g) from metastatic sites of stage III ovarian cancer patients (aged between 18 and 70 years) were obtained during primary debulking surgery. Tumor specimens were mechanically disaggregated into suspensions of small tumor clumps. Tissue culture was carried out as previously reported $(20,21)$ : malignant cells were suspended in soft agarose and growth media at $\sim 30,000$ cells per well in 24-well plates and exposed to various chemotherapeutic agents, including cisplatin, carboplatin, paclitaxel and docetaxel. Treated cell suspensions were incubated for $72 \mathrm{~h}$, at $37^{\circ} \mathrm{C}$ in a $5 \% \mathrm{CO}_{2}$ atmosphere with drug and then pulsed with $\left[{ }^{3} \mathrm{H}\right]$-thymidine $(5 \mu \mathrm{Ci} /$ well $)$ to measure the level of DNA synthesis. After an additional $48 \mathrm{~h}$ incubation period, cells were harvested onto glass fiber filters and the incorporated radioactivity was measured by liquid scintillation. Positive and negative controls were performed as previously reported (20,21). EDR score was evaluated, as previously reported (22).

Apoptosis assessment by Annexin V staining. After drug treatments, cells were resuspended in $200 \mu 1$ staining solution (containing Annexin $\mathrm{V}$ fluorescein and propidium iodide in a Hepes buffer, Annexin V-FITC staining kit, Pharmingen, San Jose, CA, USA). Following incubation at room temperature for $15 \mathrm{~min}$, cells were analyzed by flow cytometry. Annexin V binds to those cells that express phosphatidylserine on the outer layer of the cell membrane and propidium iodide stains the cellular DNA of those cells with a compromised cell membrane. This allows for the discrimination of live cells (unstained with either fluorochrome) from apoptotic cells 
A

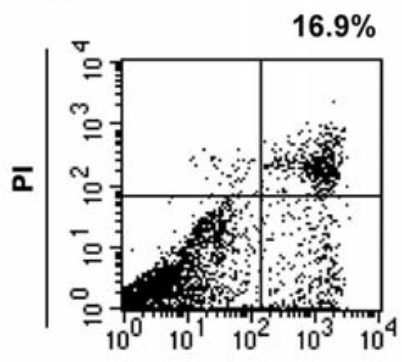

$17.2 \%$

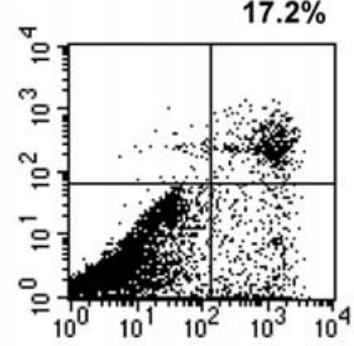

$56.2 \%$

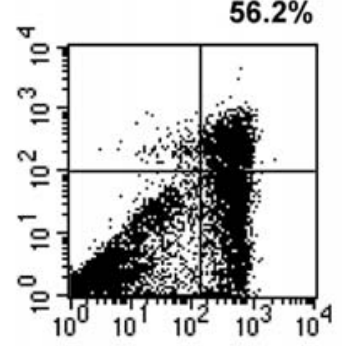

$71.5 \%$

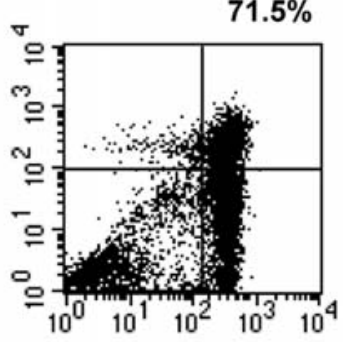

ANNEXIN V

B

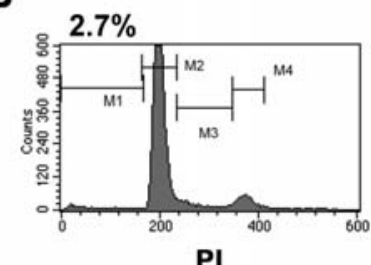

C

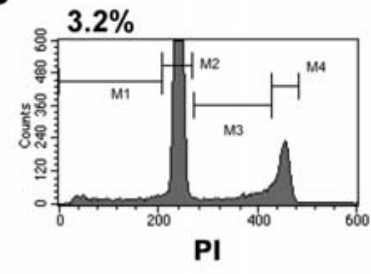

C

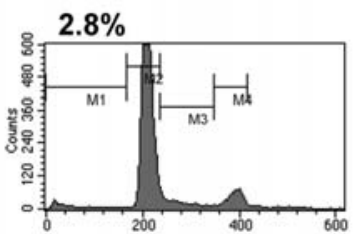

PI

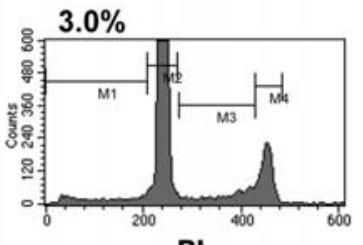

TRAIL

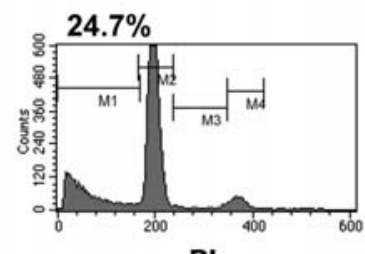

PI

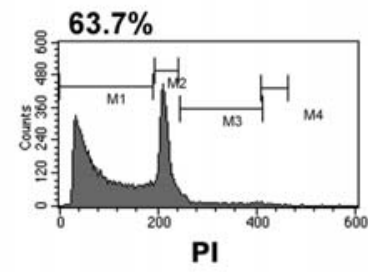

BZ

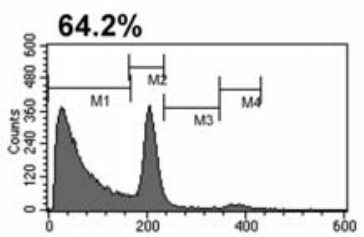

PI

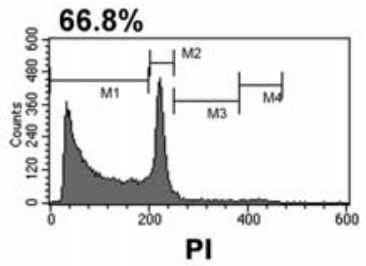

BZ+TRAIL

Figure 1. Flow cytometric analysis of Annexin V binding (A) and PI DNA labeling (B and C) of primary ovarian cancer cells treated with either no additives (C) or $50 \mathrm{ng} / \mathrm{ml}$ TRAIL or $0.5 \mu \mathrm{M}$ bortezomib (BZ) or both bortezomib and TRAIL at the above concentrations. (A) Apoptotic cells are present in the top and bottom right squares. (B and C) Hypodiploid, apoptotic cells are included within the M1 gate; M2 corresponds to $\mathrm{G}_{0} / \mathrm{G}_{1}$ cells, $\mathrm{M} 3$ to S-phase cells and $\mathrm{M}_{4}$ to $\mathrm{G}_{2} / \mathrm{M}$-phase cells. In each panel the percentage of apoptotic cells is indicated. B and C correspond to two different patients.

(stained only with Annexin V) and necrotic cells (stained with both Annexin $\mathrm{V}$ and propidium iodide).

Quantification of apoptosis and cell cycle analysis by propidium iodidelfluorescence activated cell sorting. Cells were harvested with trypsin, washed, fixed and resuspended in $400 \mu \mathrm{l}$ of propidium iodide (PI) solution $(50 \mu \mathrm{g} / \mathrm{ml} \mathrm{PI,} 0.1 \%$ Triton X-100 and $0.1 \%$ sodium citrate in PBS) (Cycle Plus DNA staining kit, Becton-Dickinson, USA). The cells were then analyzed by flow cytometry using software dedicated for DNA analysis (ModFit LT software, Verity Software House, Topsham, ME, USA). The cells with subdiploid DNA content were quantified to determine the percentage of cells containing apoptotic, fragmented DNA.

Reagents used to induce apoptosis of tumor cells. Recombinant human TRAIL (rh superkiller TRAIL) was purchased from Alexis Co. (Lausen, Switzerland). In some experiments the cells were preincubated with a pan-caspase inhibitor, $\mathrm{N}$ benzyloxy-carbonyl-Val-Ala-Asp(OMe)-fluoromethylketone (zVADfmk, Sigma, St. Louis, USA) before the addition of the various compounds stimulating apoptosis.

The agonistic monoclonal antibodies to TRAIL-R 1 (mapatumumab) and TRAIL-R2 (lexatumumab) are fully human antibodies of IgG1 isotype (18) and were generously provided by Human Genome Sciences, Inc. (Rockville, MD, USA).

Western blot analysis. Whole cell extracts were obtained lysing the cells in a buffer containing $20 \mathrm{mM}$ HEPES, $50 \mathrm{mM}$ $\mathrm{NaCl}, 10$ mM EDTA, 2 mM EGTA, 0.5\% NP-40, 1 mM DTT, $0.1 \mathrm{mM}$ PMSF, $2 \mu \mathrm{g} / \mathrm{ml}$ leupeptin, $2 \mu \mathrm{g} / \mathrm{ml}$ aprotinin, $25 \mathrm{mM}$ $\mathrm{NaF}$ and $10 \mathrm{mM} \mathrm{Na} \mathrm{VO}_{4}$. After incubation for $30 \mathrm{~min}$ on ice, the protein lysates were cleared of debris by centrifugation at $10,000 \mathrm{x} g$ for $10 \mathrm{~min}$. The protein concentration in the soluble supernatant, was determined using the Bio-Rad protein assay (Bio-Rad, Richmond, VA, USA).

Antibodies. Anti-caspase-8 was purchased from Upstate (Upstate Biotechnology, Lake Placid, NY, USA).

\section{Results}

Primary ovarian cancer cells are sensitive to the proapoptotic effects of bortezomib. In a first set of experiments we evaluated the effect of bortezomib on primary ovarian cancer cells. We then isolated primary ovarian cancer cells from 34 patients undergoing debulking surgery and these cells were 


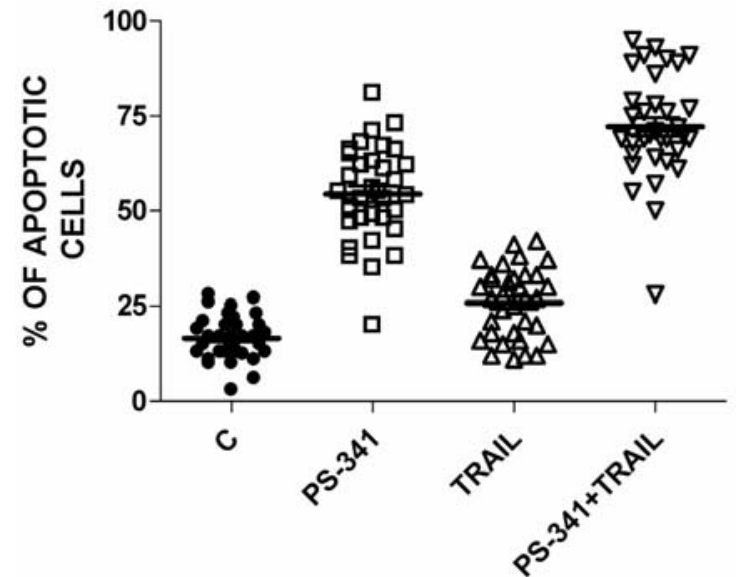

Figure 2. Percentage of apoptotic cells of 34 primary ovarian cancer cells grown for $16 \mathrm{~h}$ either in the absence (C) or in the presence of $0.5 \mu \mathrm{M}$ bortezomib or $50 \mathrm{ng} / \mathrm{ml}$ TRAIL or both bortezomib and TRAIL at the above concentrations. The proportion of apoptotic cells was evaluated by Annexin V binding assay. The difference between bortezomib and $\mathrm{C}$ and between TRAIL and bortezomib + TRAIL was highly significant $(\mathrm{p}<0.001)$. The bars correspond to mean values \pm SEM.

grown either in the absence or in the presence of bortezomib or TRAIL or both agents. To evaluate the effect of these molecules on the apoptosis of ovarian cancer cells we assessed after 16-20 $\mathrm{h}$ of incubation the percentage of cells that bind Annexin V (an early marker of apoptosis) (Fig. 1A) and after $36-48 \mathrm{~h}$ the percentage of hypodiploid cells (cells with reduced DNA content due to its degradation, a late marker of apoptosis), both by flow cytometry (Fig. 1B and C). The results of these studies showed that: i) bortezomib elicited a pronounced proapoptotic effect on ovarian cancer cells ( $\mathrm{p}<0.001$, when compared to $\mathrm{C}$ ); ii) TRAIL when added alone elicited only a weak cytotoxic effect $(p<0.05$, when compared to C); iii) TRAIL, when added in combination with bortezomib, potentiated the proapoptotic effects of bortezomib $(\mathrm{p}<0.001$, when bortezomib + TRAIL was compared to bortezomib alone) (Fig. 2).

The inspection of individual cases showed that: i) bortezomib was able to markedly enhance the proportion of apoptotic cells in $33 / 34$ cases ii) the cytotoxic response to bortezomib was heterogeneous ranging from 22 to $80 \%$; iii) bortezomib + TRAIL increased the proportion of apoptotic cells compared to bortezomib alone in 34/34 cases (Fig. 2).

Ovarian cancer cells resistant to cisplatin or paclitaxel are sensitive to bortezomib. The cells of the 34 ovarian cancer patients evaluated for their sensitivity to bortezomib and TRAIL were assessed also for the in vitro sensitivity to cisplatin and paclitaxel using the EDR assay. The results of this assay showed that $7 / 34$ and 8/34 cases were extremely resistant to cisplatin and paclitaxel, respectively (Fig. 3). The analysis of the sensitivity of cisplatin-resistant and paclitaxel-resistant cases, compared to sensitive cases

A
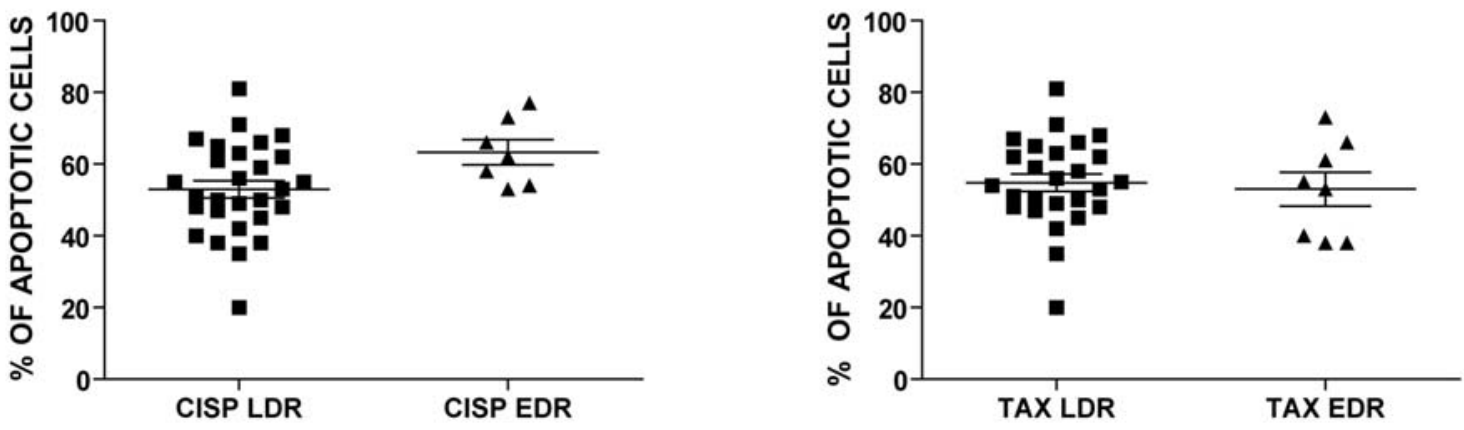

B
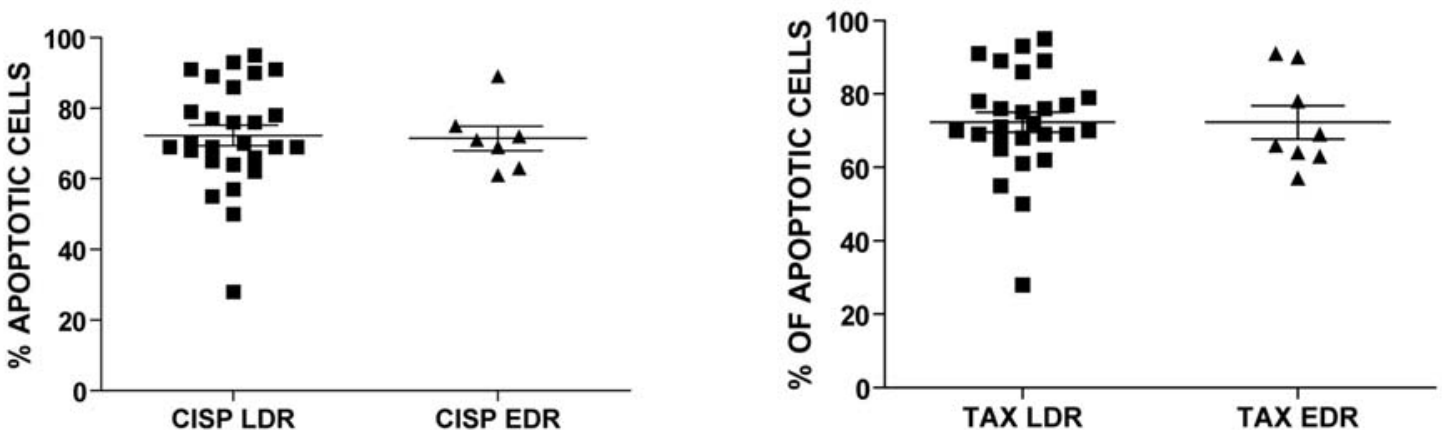

Figure 3. Percentage of apoptotic cells observed in 34 primary ovarian cancer cells subdivided into cisplatin low resistant (CISP LDR) and cisplatin extremely resistant (CISP EDR) or paclitaxel low resistant (TAX LDR) and paclitaxel extremely resistant (TAX EDR). The data are reported for cells incubated with bortezomib alone (A) or in combination with TRAIL (B). The differences between CISP LDR and CISP EDR or TAX LDR and TAX EDR are not significant $(\mathrm{p}>0.1)$. The bars reported in the graphs represent the mean value \pm SEM. 


\section{A}

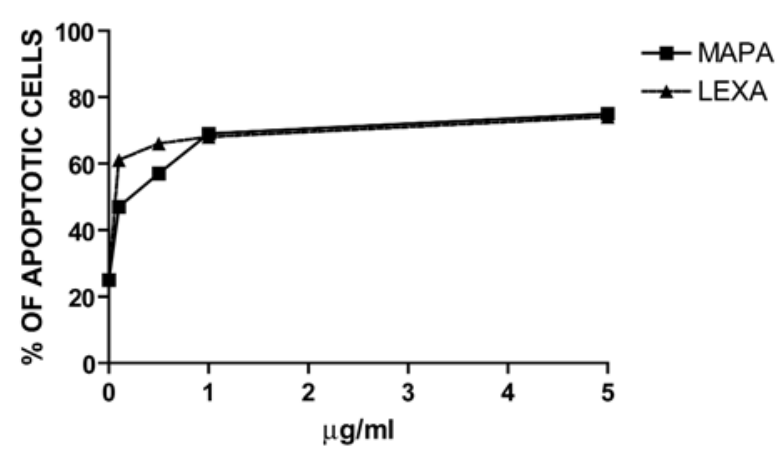

B

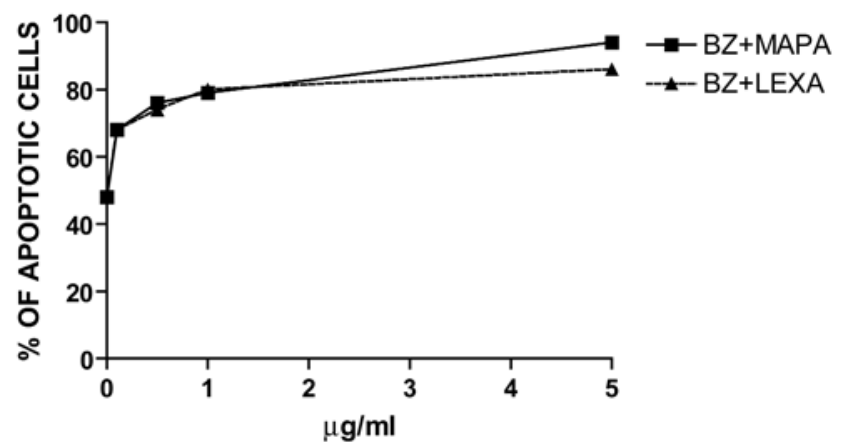

Figure 4. Percentage of apoptotic cells observed in one representative case of primary ovarian cancer cells incubated for $24 \mathrm{~h}$ in the presence of increasing concentrations of either mapatumumab (mapa) or lexatumumab (lexa). In the experiments reported in A the antibodies were added alone, while in the experiments reported in $\mathrm{B}$ were added in combination with a fixed dose of $0.5 \mu \mathrm{M}$ bortezomib.

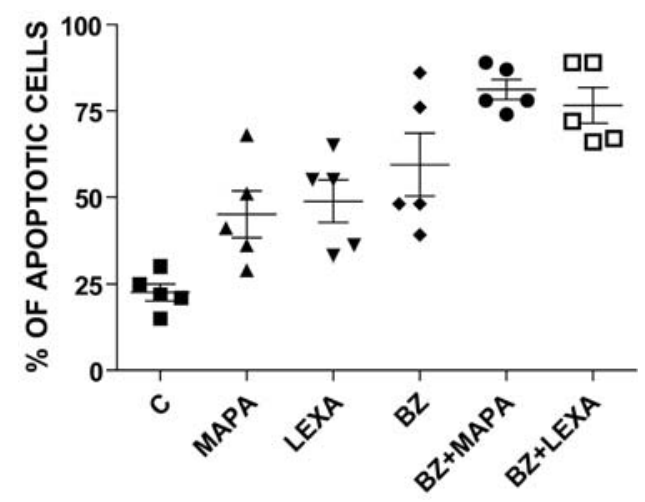

Figure 5. Percentage of apoptotic cells of 5 cases of primary ovarian cancer cells grown for $16 \mathrm{~h}$ either in the absence (C) or in the presence of $1 \mu \mathrm{g} / \mathrm{ml}$ mapatumumab (mapa) or $1 \mu \mathrm{g} / \mathrm{ml}$ lexatumumab (lexa) or $0.5 \mu \mathrm{M}$ bortezomib or mapatumumb + bortezomib or lexatumumab + bortezomib. The proportion of apoptotic cells was determined by Annexin V binding assay.

showed comparable levels of sensitivity to either bortezomib (Fig. 3A) or bortezomib + TRAIL (Fig. 3B).

Mapatumumab and lexatumumab improve the proapoptotic effect of bortezomib on ovarian cancer cells. Mapatumamab and lexatumumab are fully human agonistic monoclonal

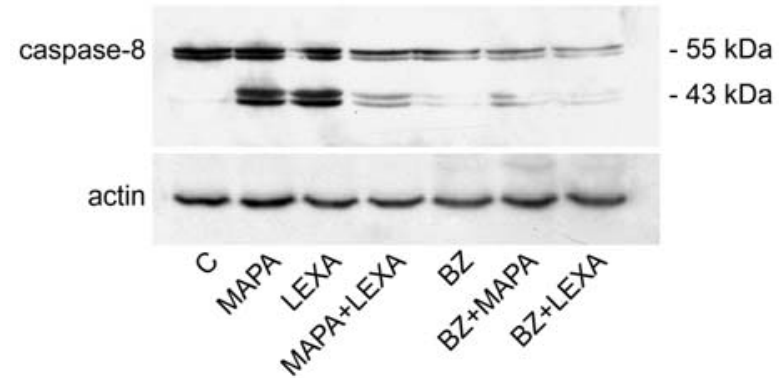

Figure 6. Bortezomib-induced sensitization to the extrinsic TRAIL receptormediated pathway of apoptosis in primary ovarian cancer cells. Immunoblots of caspase- 8 expression in whole lysates of a case of primary ovarian cancer cells that were treated with media $(\mathrm{C})$ or treated for $20 \mathrm{~h}$ with $1 \mu \mathrm{g} / \mathrm{ml}$ mapatumumab, $1 \mu \mathrm{g} / \mathrm{ml}$ lexatumumab or $1 \mu \mathrm{g} / \mathrm{ml}$ of both. Additional treatments included $0.5 \mu \mathrm{M}$ bortezomib alone or in combination with $+1 \mu \mathrm{g} / \mathrm{ml}$ of mapatumumab or lexatumumab. A representative blot from three different experiments is shown.

antibodies specific for TRAIL-R1 and TRAIL-R2; respectively, which induce TRAIL-R apoptotic signaling. We have therefore evaluated the biologic effects induced by these two antibodies added alone or in combination with bortezomib.

In a first set of experiments we added different doses of mapatumumab and lexatumumab (from 0.1 to $5 \mu \mathrm{g} / \mathrm{ml}$ ) of bortezomib alone (Fig. 4A) or in combination with $0.5 \mu \mathrm{M}$ bortezomib (Fig. 4B) to primary ovarian cancer cells. Interestingly, both mapatumumab and lexatumumab induced a significant pro-apoptotic effect, reaching their maximal effect at $1 \mu \mathrm{g} / \mathrm{ml}$ (Fig. 4A and B). Importantly, the effect of these agonistic TRAIL-R mAbs was greater than the effect of TRAIL alone (see Fig. 2).

In a second set of experiments we evaluated the effects of a fixed amount of either mapatumumab or lexatumumab $(1 \mu \mathrm{g} / \mathrm{ml})$ added alone or in combination with bortezomib on the induction of apoptosis of 5 cases of primary ovarian cancer. The results of this analysis showed that: i) both mapatumumab (mapa) and lexatumumab (lexa) induced, when added alone, a moderate, but significant increase in the proportion of apoptotic cells (mapa-treated cells vs. control, $\mathrm{p}<0.01$; lexa-treated cells vs. control, $\mathrm{p}<0.01$ ); ii) both mapatumumab and lexatumumab significantly increased the rate of apoptotic cells induced by bortezomib and uniformly affected all patient samples (mapa + bortezomib-treated cells vs. bortezomib-treated cells, $\mathrm{p}<0.05$; lexa + bortezomib-treated cells vs. bortezomib-treated cells p<0.05) (Fig. 5).

A critical step in TRAIL signalling after receptor aggregation is thought to be the dimerization of pro-caspase- 8 in the death-inducing signalling complex (23), which confers a conformational change that is required for its enzymatic activity (24). Increased enzymatic activation of caspase- 8 and accumulation of the cleaved form (43 kDa), associated with a decline of pro-caspase- $8(55 \mathrm{kDa})$ was observed in primary ovarian cancer cells treated with mapatumumab or lexatumumab, particularly when added in combination with bortezomib (Fig. 6): it was noted that the accumulation of the cleaved $43 \mathrm{kDa}$ bands is particularly evident in cells treated with mapatumumab or lexatumumab, while in samples treated with bortezomib alone or in combination with the two TRAIL-R mAbs the decline of pro-caspase- 8 was very pronounced (Fig. 6). 


\section{Discussion}

The ubiquitin-proteasome pathway is involved in intracellular protein turnover and its regulated control is essential for cell homeostasis. The studies carried out in the last 10 years have shown that several proteasome inhibitors are potent anticancer drugs for their property to induce programmed cell death preferentially in transformed cells. These studies have contributed to introduce bortezomib into the clinic. It is registered for the treatment of multiple myeloma and mantle cell lymphoma. This drug, when administered with established anti-cancer agents, elicited impressive results in the treatment of multiple myeloma (25). In vitro and in vivo studies have in part elucidated the mechanism of actions of this drug, the toxicity profile and clinical efficacy and have also lead to the identification of biochemical pathways involved in the resistance to this agent (reviewed in refs. 26 and 27).

On the basis of the results obtained in multiple myeloma clinical studies with bortezomib have been carried out in other tumors, including ovarian cancer. The studies carried out in this cancer are at present limited to phase I studies aimed to define the clinical toxicity profile of bortezomib when administered either with cisplatin or paclitaxel (10-12). In the present study we have explored the sensitivity of a panel of primary ovarian cancer to bortezomib added alone or in combination with TRAIL. Our results showed that the large majority of these tumors were sensitive to bortezomib and, particularly, to bortezomib + TRAIL.

We have included in our study only ovarian cancer patients at disease presentation. The analysis of in vitro chemoresistance through the EDR assay showed that $19 \%$ of patients are extremely drug resistant for cisplatin and $24 \%$ for paclitaxel. Previous studies have shown that the EDR assay was accurate $(99 \%)$ in predicting in vivo chemoresistance (2022). Interestingly, these chemoresistant patients displayed a bortezomib sensitivity comparable to that observed for nonchemoresistant patients. This observation suggests that the bortezomib + TRAIL treatment could be of value in the treatment of chemoresistant ovarian cancer disease.

Our results further support previous studies, mainly based on the analysis of ovarian cancer cell lines, showing a significant sensitivity of ovarian cancer cells to the proapoptotic effects of bortezomib. Proteasome inhibitors induce cell death of ovarian cancer cells through different molecular mechanisms involving BH3-only ptotein stabilization (8), endoplasmic reticulum stress response (28) and oxidative stress (8).

Our results showed also that the cytotoxic effects of bortezomib on ovarian cancer cells were potentiated by the death ligand TRAIL or by agonistic TRAIL-R1 and TRAIL-R2 mAbs. This observation confirms and extends previous studies, mainly based on the analysis of ovarian cancer cell lines and showing that bortezomib greatly potentiates the proapoptotic effect of TRAIL $(8,28,29)$. It is of interest to note that recent preclinical studies have provided both a molecular basis and a translationally relevant proof of principle for the therapeutic combination of the proteasome inhibitor bortezomib with death receptor agonist monoclonal antibodies or recombinant TRAIL in vivo to efficiently promote tumor cell apoptosis (30). These observations are of interest in view of future clinical applications. In fact, as above mentioned, fully human TRAIL- R1 and TRAIL-R2 $\mathrm{mAbs}$ have been developed and introduced into clinic and tested in phase I/II clinical studies in various tumors, including ovarian cancer (31). In one of these studies 9 ovarian cancer patients with advanced disease were treated with mapatumumab and 3 of them experienced a long-lasting stable disease (31). Importantly, phase I studies also indicate that mapatumumab and lexatumumab are safe and have acceptable toxicity profiles $(31,32)$. On the other hand, an improved recombinant form of TRAIL, which exerts no toxicity in normal human cells, is being currently evaluated in clinical trials (33).

Biochemical studies carried out in primary ovarian cancer cells (the present study) and in ovarian cancer cell lines (8) suggest that bortezomib-induced amplification of caspase- 8 activation in response to TRAIL is important for enhanced apoptosis of ovarian cancer cells treated with bortezomib and TRAIL. This crucial role of caspase- 8 activation is in agreement with previous studies on bortezomib sensitization of human hepatoma cells to TRAIL (34). Furthermore, we observed that the overexpression of c-FLIP, an antagonist of caspase-8, restores a low sensitivity to the proapoptotic effects of bortezomib + TRAIL.

In conclusion, the findings of the present study suggest that bortezomib combined with TRAIL or TRAIL-R1 and TRAIL-R2 agonistic monoclonal antibodies may be a useful treatment for ovarian cancer.

\section{Acknowledgements}

We are grateful to the Human Genome Science Company (Rockville, MD, USA) for the generous gift of mapatumumab and lexatumumab. We extend our thanks to Dr J. Humphreys of the Human Genome Science Company for critical reading of the manuscript. We thank G. Loreto for graph preparation. This study was supported by a special grant from Italian Health Ministry.

\section{References}

1. Cannistra SA: Cancer of the ovary. N Eng1 J Med 351: 2519-2529, 2004.

2. Goldberg AL, Stein R and Adams J: New insights into proteasome function: from archaebacteria to drug development. Chem Biol 2: 503-508, 1995.

3. Palombella VJ, Rando OJ, Goldberg AL and Maniatis T: The ubiquitin-proteasome pathway is required for processing of the $N F-\kappa B 1$ precursor protein and the activation of NF- $\mathrm{KB}$. Cell 78 : 773-785, 2000.

4. Wong CY, Mayo MW and Balwin AS Jr: TNF- and cancer therapy-induced apoptosis: potentiation by inhibition of NFкарраB. Science 274: 784-787, 1996.

5. Lashinger LM, Zhu K, Willimas SA, Shrader M, Dinney CP and McConkey DJ: Bortezomib abolishes tumor necrosis factorrelated apoptosis-inducing ligand resistance via a p21-dependent mechanism in human bladder and prostate cancer cells. Cancer Res 65: 4902-4908, 2005.

6. Frankel A, Man S, Elliott P, Adams J and Kerbel RS: Lack of multicellular drug resistance observed in human ovarian and prostate carcinoma treated with the protesome inhibitor PS-341. Clin Cancer Res 6: 3719-3728, 2000.

7. Zhu H, Zhang L, Dong F, Guo W, Wu S, Teraishi F, Davis JJ, Chiao PJ and Fang B: Bik/NBK accumulation correlates with apoptosis-induction by bortezomib (PS-341, Velcade) and other proteasome inhibitors. Oncogene 24: 4993-4999, 2005. 
8. Saulle E, Petronelli A, Pasquini L, Petrucci E, Mariani G, Biffoni M, Ferretti G, Scambia G, Benedetti-Panici PL, Cognetti F, Humphreys R, Peschle C and Testa U: Proteasome inhibitors sensitize ovarian cancer cells to TRAIL induced apoptosis. Apoptosis 12: 635-655, 2007.

9. Bazzaro M, Lee MK, Zoso A, Stirling W, Santillan A, Shih IeM and Roden RB: Ubiquitin-proteasome system stress sensitizes ovarian cancer to proteasome inhibitor-induced apoptosis. Cancer Res 66: 3754-3763, 2006.

10. Aghjanian C, Dizon DS, Sabbatini P, Raizer JJ, Dupont J and Spriggs DR: Phase I trial bortezomib and carboplatin in recurrent ovarian or primary peritoneal cancer. J Clin Oncol 23: 5943-5949, 2005.

11. Ramirez PT, Landen CN Jr, Coleman RL, Milam MR, Levenback C, Johnston TA and Gershenson DM: Phase I trial of the proteasome inhibitor bortezomib in combination with carboplatin in patients with platinum- and taxane-resistant ovarian cancer. Gynecol Oncol 108: 68-71, 2008.

12. Cresta S, Sessa C, Catapano CV, Gallerani E, Passalacqua D, Rinaldi A, Bertoni F, Viganò L, Maur M, Capri G, Maccioni E, Tosi D and Gianni L: Phase I study of bortezomib with weekly paclitaxel in patients with advanced solid tumors. Eur J Cancer 44: 1829-1834, 2008.

13. Ashkenazi A: Targeting death and decoy receptors of the tumornecrosis factor superfamily. Nat Rev Cancer 2: 420-431, 2002.

14. Bouralexis S, Findley DM and Evdokiou A: Death to the bad guys: targeting cancer via Apo2L/TRAIL. Apoptosis 10: 35-51, 2005 .

15. Kimberley FC and Sereaton GR: Following a TRAIL: update on a ligand and its five receptors. Cell Res 14: 359-372, 2004.

16. Duiker EW, Mom CH, de Jong S, et al: The clinical trial of TRAIL. Eur J Cancer 42: 2233-2240, 2006.

17. Meng XW, Lee SH and Kaufmann SH: Apoptosis in the treatment of cancer: a promise kept? Curr Opin Cell Biol 18: 668-676, 2006.

18. Pukac L, Kanakaraj P, Humphreys R, Alderson R, Bloom M, Sung C, Riccobene T, Johnson R, et al: HGS-ETR1, a fully human TRAIL-receptor 1 monoclonal antibody, induces death in multiple tumor types in vitro and in vivo. Br J Cancer 92: 1430-1441, 2005

19. Pasquini L, Petrucci E, Riccioni R, Petronelli A and Testa U: Sensitivity and resistance of human cancer cells to TRAIL: mechanisms and therapeutical perspectives. Cancer Ther 4: 47-72, 2006.

20. Kern DH and Weisenthal LM: Highly specific prediction of antineoplastic drug resistance with an in vitro assay utilizing suprapharmacological drug exposures. J Natl Cancer Inst 82: $582-588,1990$

21. Frehauf JP and Manetta A: Use of the extreme drug resistance assay to evaluate mechanisms of resistance in ovarian cancer: taxol resistance and MDR-1 expression. Contrib Gynecol Ostet 19: 39-52, 1994
22. Hollaway RW, Mehta RS, Finkler NJ, Li KT, McLaren CE, Parker RJ and Fruehauf JP: Association between in vitro platinum resistance in the EDR assay and clinical outcomes for ovarian cancer patients. Gynecol Oncol 87: 8-16, 2002.

23. Peter ME and Krammer PH: The CD95 (APO-1/Fas) DISC and beyond. Cell Death Diff 10: 26-35, 2003.

24. Boatright KM, Renatus M, Scott FL, et al: A unified model for apical caspases activation. Mol Cell 11: 529-541, 2003.

25. Richardson PG, Mitsiades C, Schlossman R, Ghobrial I, Hideshima T, Munshi N and Anderson KC: Bortezomib in the front-line treatment of multiple myeloma. Expert Rev Anticancer Ther 8: 1053-1072, 2008.

26. Teicher BA: Newer cytotoxic agents: attacking cancer broadly. Clin Cancer Res 14: 1610-1617, 2008.

27. Orlowski RZ and Kuhn DJ: Proteasome inhibitors in cancer therapy: lessons from the first decade. Clin Cancer Res 14: 1649-1657, 2008.

28. Bruning A, Burger P, Vogel M, Rahmeh M, Friese K, Lehard M and Burges A: Bortezomib treatment of ovarian cancer cells mediates endoplasmic reticulum stress, cell cycle arrest, and apoptosis. Invest New Drugs (In press).

29. Woods DC, Liu HK, Nishi Y, Yanase T and Johnson AL: Inhibition of proteasome activity sensitizes human granulose tumor cells to TRAIL-induced cell death. Cancer Lett 260: 20-27, 2008.

30. Shanker A, Brooks AD, Tristan CA, Wine JW, Elliott PJ, Yagita H, Takeda K, Smyth MJ, Murphy WJ and Sayers TJ: Treating metastatic solid tumors with bortezomib and a tumor necrosis factor-related apoptosis-inducing ligand receptor agonist antibody. J Natl Cancer Inst 100: 649-662, 2008.

31. Hotte SJ, Hirte HW, Chen EX, Siu LL, Le LH, Corey A, Iacobucci A, MacLean M, Lo L, Fox NL and Oza AM: A phase 1 study of mapatumumab (fully human monoclonal antibody to TRAIL-R1) in patients with advanced solid malignancies. Clin Cancer Res 14: 3450-3455, 2008.

32. Plummer R, Attard G, Pacey S, Li L, et al: Phase I and pharmacokinetic study of lexatumumab in patients with advanced cancer. Clin Cancer Res 13: 6187-6194, 2007.

33. Ashkenazi A, Holland P and Eckardt SG: Ligand-based targeting of apoptosis in cancer: the potential of recombinant human apoptosis ligand 2/tumor necrosis factor-related apoptosis-inducing ligand (rhApo2L/TRAIL). J Clin Oncol 26 3621-3630, 2008

34. Ganten TM, Koschny R, Haas TL, et al: Proteasome inhibition sensitizes hepatoma carcinoma cells, but not human hepatocytes, to TRAIL. Hepatology 42: 588-597, 2005. 